www.nature.com/ejhg

\title{
Low frequency of MECP2 mutations in mentally retarded males
}

\author{
Helger G Yntema*, ${ }^{*}$, Tjitske Kleefstra ${ }^{1}$, Astrid R Oudakker ${ }^{1}$, Tom Romein ${ }^{2}$, Bert BA de Vries ${ }^{1}$, \\ Willy Nillesen ${ }^{1}$, Erik A Sistermans ${ }^{1}$, Han G Brunner ${ }^{1}$, Ben CJ Hamel $^{1}$ and \\ Hans van Bokhoven ${ }^{1}$
}

${ }^{1}$ Department of Human Genetics, University Medical Center, Nijmegen, The Netherlands; ${ }^{2}$ De Hondsberg, ChildPsychiatry Observation Institute, Oisterwijk, The Netherlands

\begin{abstract}
A high frequency of mutations in the methyl CpG-binding protein 2 (MECP2) gene has recently been reported in males with nonspecific X-linked mental retardation. The results of this previous study suggested that the frequency of MECP2 mutations in the mentally retarded population was comparable to that of CGG expansions in FMR1. In view of these data, we performed MECP2 mutation analysis in a cohort of $\mathbf{4 7 5}$ mentally retarded males who were negative for FMR1 CGG repeat expansion. Five novel changes, detected in seven patients, were predicted to change the MECP2 coding sequence. Except for one, these changes were not found in a control population. While this result appeared to suggest a high mutation rate, this conclusion was not supported by segregation studies. Indeed, three of the five changes could be traced in unaffected male family members. For another change, segregation analysis in the family was not possible. Only one mutation, a frameshift created by a deletion of two bases, was found to be de novo. This study clearly shows the importance of segregation analysis for low frequency mutations, in order to distinguish them from rare polymorphisms. The true frequency of MECP2 mutations in the mentally retarded has probably been overestimated. Based on our data, the frequency of MECP2 mutations in mentally retarded males is $0.2 \%(1 / 475)$.
\end{abstract}

European Journal of Human Genetics (2002) 10, 487-490. doi:10.1038/sj.ejhg.5200836

Keywords: MECP2; mental retardation; mutation frequency

Mutations in the methyl-CpG binding protein 2 (MECP2; MIM 300005) gene have first been described in Rett syndrome (RTT; MIM 312750), a progressive neurologic developmental disorder. ${ }^{1}$ As RTT occurs almost exclusively in females, it has been proposed that RTT is caused by an $\mathrm{X}$-linked dominant mutation with lethality in hemizygous males. However, MECP2 mutations have now been reported in severely retarded males with progressive neurological symptoms, ${ }^{2-6}$ in males with non-progressive encephalopathy, ${ }^{7}$ and in males with an Angelman-like phenotype. ${ }^{8}$ Recently, recessive mutations have also been described in

*Correspondence: HG Yntema, Department Human Genetics, University Medical Centre Nijmegen, PO Box 9101, 6500 HB Nijmegen,

The Netherlands. Tel: 0031-24-3616696; Fax: 0031-24-3540488;

E-mail: H.Yntema@antrg.azn.nl

Received 6 February 2002; revised 3 May 2002; accepted 7 May 2002 males from families with nonspecific X-linked mental retardation (MRX). ${ }^{9-11}$

Of all reported MRX genes, MECP2 may have the highest mutation frequency. MECP2 mutations that do not cause RTT in females have been found in families with X-linked mental retardation that were previously linked to Xq28. ${ }^{5,10,11}$ In addition, based on an analysis of the MECP2 gene in 185 sporadic MR males, Couvert et al ${ }^{10}$ suggested that mutations in $M E C P 2$ are responsible for $\sim 2 \%$ of mental retardation in males. This indicates that the frequency of MECP2 mutations equals that of Fragile-X syndrome. ${ }^{12}$ This hypothesis prompted us to perform MECP2 mutation analysis on the DNA of 475 mentally retarded males, who were negative for the CGG repeat expansion in the FMR1 gene, and had a normal $46(\mathrm{X}, \mathrm{Y})$ karyotype. Informed consent was obtained in all instances. 
No pre-selection based on degree of mental retardation and presence of additional dysmorphic or neurologic abnormalities was made. We performed mutation analysis of the coding region and splice sites of the MECP2 gene by direct sequencing of PCR-amplified genomic DNA (five fragments, primer sequences are available upon request). Fourteen different sequence changes were detected. Of these changes, four were reported previously as non-pathogenic variants, and five were novel silent changes (Table 1). Five changes were possible mutations not described before (Table 2). The latter group included four amino acid changes and a deletion of two bases resulting in a frameshift and premature stopcodon. The T196S change was found in three patients of different families.

Following the detection of four novel amino acid changes, we investigated the DNA of 150 control males for these changes by allele-specific oligonucleotide hybridization. The T196S mutation was found in one of the controls. The other amino acid changes were not detected in the control population. Sequence analysis revealed that all mothers of the patients were heterozygous (carriers) for the missense mutation. For three amino acid changes segregation studies were performed. All changes were found in male family members with normal IQ, including grandfathers, maternal uncles and healthy brothers of the index patient. These results indicate that the changes T196S,

Table 1 Silent changes and known non-pathogenic variants in 475 MR males

\begin{tabular}{|c|c|c|c|}
\hline $\begin{array}{l}\text { Nucleotide } \\
\text { change }\end{array}$ & $\begin{array}{l}\text { Amino } \\
\text { acid effect }\end{array}$ & $\begin{array}{l}\text { Frequency } \\
\text { in this study }\end{array}$ & Reference \\
\hline $225 \mathrm{G} \rightarrow \mathrm{A}$ & P75P & $1 / 475$ & This study \\
\hline $528 \mathrm{C} \rightarrow \mathrm{G}$ & P176P & $1 * / 475$ & This study \\
\hline $573 \mathrm{C} \rightarrow \mathrm{G}$ & P191P & $1 / 475$ & This study \\
\hline $582 \mathrm{C} \rightarrow \mathrm{T}$ & S194S & $2 / 475$ & 17 \\
\hline $686 \mathrm{C} \rightarrow \mathrm{T}$ & S229L & $1 / 475$ & 17 \\
\hline $834 \mathrm{C} \rightarrow \mathrm{T}$ & A287A & $1 / 475$ & 6 \\
\hline $897 \mathrm{C} \rightarrow \mathrm{T}$ & T299T & $1 * / 475$ & 17 \\
\hline $942 \mathrm{C} \rightarrow \mathrm{T}$ & |314| & $1 / 475$ & This study \\
\hline $1189 \mathrm{G} \rightarrow \mathrm{A}$ & E397K & $1 / 475$ & 18 \\
\hline
\end{tabular}

${ }^{*}$ One of the patients has two silent changes: T299T and P176P
E394K, and P480S are rare polymorphisms instead of disease causing mutations.

The T228S amino acid change was inherited from the mother, but no other family members were available for further segregation analysis. In this case, it is impossible to distinguish between a rare non-pathogenic variant and a causative mutation. The threonine at position 228 however is not conserved in mouse (alanine), rat (alanine) and chicken (glycine), indicating that it is unlikely that the change has a dramatic effect on the MECP2 protein.

The 1415-1416del mutation was found hemizygously in the patient and was absent in the DNA of the mother. Thus, this is the first reported de novo MECP2 mutation in a male. Somatic mosaicism for a MECP2 mutation in males, ${ }^{2,3}$ as well as inherited MECP2 mutations in males have been previously described. ${ }^{4-11}$ The $1415-1416$ del mutation in the 3 ' part of the gene leads to a frameshift and premature stop codon. It is predicted that C-terminal 15 amino acids are replaced by 13 other amino acids (Figure 1). Previous clinical studies showed that the patient has moderate mental retardation (IQ 45-55), emotional disturbances, gynaecomastia and generalized obesity. Results of clinical re-examination will be published elsewhere. ${ }^{13}$ MECP2 mutations in males frequently comprise amino acid substitutions or truncating mutations at the C-terminus, outside the conserved MBD and TRD domain, like in the patient reported here. ${ }^{5-7,10,11}$ Apparently, these mutations are milder than those seen in RTT, very likely because they will affect only subset of all MECP2 target genes.

Our study supports the finding of Glatt et $a l^{14}$ who suggested that rare missense variants might be more common than expected. Therefore, it is of crucial importance to perform segregation analysis in the families, once a possible mutation has been identified. Generally, a control population of males and females is screened for the change. In this study, three amino acid changes were found in $1 / 475$ patients $(0.2 \%)$. Therefore, at least 1500 chromosomes would need to be examined to determine if the frequency in normal males is significantly different from that in patients. ${ }^{15}$ Furthermore, only male chromosomes should be used as a control because MRX acts as a

Table 2 Novel amino acid changes, detected in 475 MR males

\begin{tabular}{|c|c|c|c|c|c|c|c|c|}
\hline Patient ID & $\begin{array}{l}\text { Mental } \\
\text { impairment }\end{array}$ & nt change & aa change & $\begin{array}{l}\text { Frequency in } \\
\text { MR males }\end{array}$ & $\begin{array}{l}\text { Frequency } \\
\text { in controls }\end{array}$ & Mother & Segregation & Conclusion \\
\hline 17513 & Moderate & $587 \mathrm{C} \rightarrow \mathrm{G}$ & T196S & $3 / 475$ & $1 / 150$ & carrier & healthy grandfather positive & Non-pathogenic variant \\
\hline 17307 & Mild & $587 \mathrm{C} \rightarrow \mathrm{G}$ & T196S & $3 / 475$ & $1 / 150$ & carrier & healthy maternal uncle positive & Non-pathogenic variant \\
\hline 17309 & Borderline & $587 \mathrm{C} \rightarrow \mathrm{G}$ & T196S & $3 / 475$ & $1 / 150$ & ND & ND & Non-pathogenic variant \\
\hline 17296 & Borderline & $683 C \rightarrow G$ & T228S & $1 / 475$ & $0 / 150$ & carrier & NA & $\begin{array}{l}\text { Non-pathogenic variant } \\
\text { or mutation? }\end{array}$ \\
\hline 17529 & Moderate & $1180 G \rightarrow A$ & E394K & $1 / 475$ & $0 / 150$ & carrier & healthy grandfather positive & Non pathogenic variant \\
\hline 17293 & Moderate & 1415-1416del & Frameshift & $1 / 475$ & ND & no carrier & de novo & De novo mutation \\
\hline 17012 & $\begin{array}{l}\text { Moderate- } \\
\text { severe }\end{array}$ & $1438 \mathrm{C} \rightarrow \mathrm{T}$ & P480S & $1 / 475$ & $0 / 150$ & carrier & healthy brother positive & Non-pathogenic variant \\
\hline
\end{tabular}

Mental impairment: borderline, IQ 70-85; mild, IQ 55-69; moderate, IQ 40-54; severe, IQ 25-39. ND: not determined. NA: not available. 
A

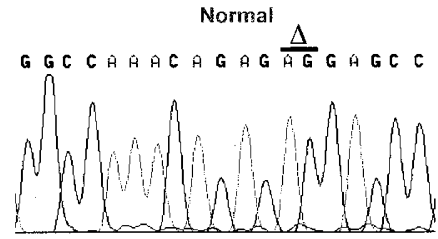

1415-1416delAG

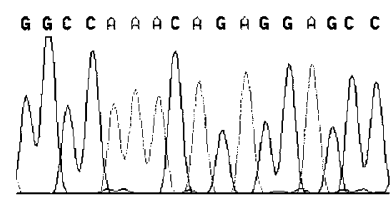

B

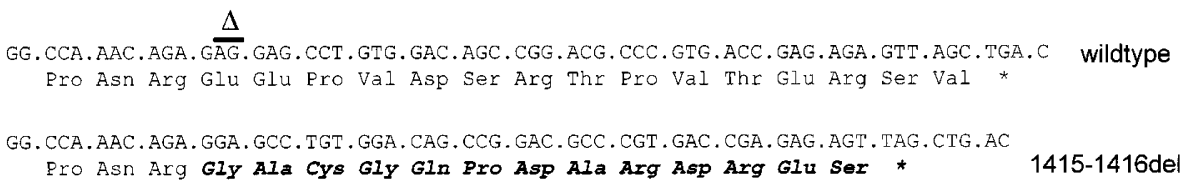

Figure 1 Mutation analysis of MECP2 in a patient with moderate mental retardation. (A) PCR products of the $3^{\prime}$ part of the last exon were sequenced and a deletion of two bases at position 1415-1416 (indicated by $\Delta$ ) was detected in the patient. (B) Wildtype DNA sequence and predicted protein are shown at the top. Below the DNA sequence and the predicted protein sequence from the patient are depicted. The 13 novel C-terminal amino acids are shown in italics.

recessive trait and a change in a control female could actually cause a phenotype when transmitted to a son. Furthermore, it is important that all sequence changes identified worldwide are deposited in the MECP2 mutation database (http://homepages.ed.ac.uk/skirmis/). For low frequency changes, the most efficient way to distinguish between a polymorphism and a disease causing mutation may be segregation analysis in the family. ${ }^{16}$

The frequency of MECP2 in the Dutch Fragile-X negative mentally retarded males is 0.2 to $0.4 \%$ (the latter figure applies if the T228S change is regarded a causative mutation). In our institute, expanded CGG repeats in the FMR1 gene are detected in $2.5 \%$ of an equal population of mentally retarded males, ie those mentally retarded males without a family history of Fragile-X syndrome (E Sistermans, unpublished observations). The difference between the MECP2 mutation frequency in our study $(1 / 475 ; 0.2-$ $0.4 \%)$ and the $2 \%(4 / 185)$ previously obtained by Couvert et $a l^{10}$ is statistically significant ( $P=0.002$; Fisher exact test). Our study revealed the importance of segregation analysis, which showed that several possible mutations were polymorphisms. In contrast to the present study, the design of the previous study did not allow contacting additional family members and segregation analysis could not be performed. The changes in the previous study were not found in 500 control chromosomes, but this amount is too low to exclude that some of the putative mutations in that study (eg P399L, R453Q) may in fact be rare polymorphisms. In conclusion, our results indicate that the incidence of MECP2 mutations in sporadic male MR is 510 -fold lower than that of Fragile-X syndrome.

\section{Acknowledgements}

We would like to thank Gerly van der Vleuten for statistical analysis. This research was supported by ZorgOnderzoek Nederland (ZON), project 2100-0041.

\section{References}

1 Hagberg B, Goutieres F, Hanefeld F, Rett A, Wilson J: Rett syndrome: criteria for inclusion and exclusion. Brain Dev 1985; 7: $372-373$.

2 Clayton-Smith J, Watson P, Ramsden S, Black GCM: Somatic mutation in MECP2 as a non-fatal neurodevelopmental disorder in males. Lancet 2000; 356: 830-832.

3 Topçu M, Akyerli C, Sayi A et al: Somatic mosaicism for a MECP2 mutation associated with classic Rett syndrome in a boy. Eur J Hum Genet 2002; 10: 77-81.

4 Villard L, Kpebe A, Cardoso C, Chelly J, Tardieu M, Fontes M: Two affected boys in a Rett syndrome family: clinical and molecular findings. Neurology 2000; 55: 1188-1193.

5 Meloni I, Bruttini M, Longo I et al: A mutation in the Rett syndrome gene, $M E C P 2$, causes X-linked mental retardation and progressive spasticity in males. Am J Hum Genet 2000; 67: $982-$ 985.

6 Hoffbuhr K, Devaney JM, LaFleur B et al: MeCP2 mutations in children with and without the phenotype of Rett syndrome. Neurology 2001; 56: 1486-1495.

7 Imessaoudene B, Bonnefont JP, Royer G et al: MECP2 mutation in non-fatal, non-progressive encephalopathy in a male. J Med Genet 2001; 38: 171-174.

8 Watson P, Black G, Ramsden S et al: Angelman syndrome phenotype associated with mutations in MECP2, a gene encoding a methyl CpG binding protein. J Med Genet 2001; 38: 224-228.

9 Orrico A, Lam CW, Galli L et al: MECP2 mutation in male patients with non-specific X-linked mental retardation. FEBS Lett 2000; 481: $285-288$.

10 Couvert P, Bienvenu T, Aquaviva C et al: MECP2 is highly mutated in X-linked mental retardation. Hum Mol Genet 2001; 10: 941 946.

11 Yntema HG, Oudakker AR, Kleefstra T et al: In frame deletion in MECP2 causes mild nonspecific mental retardation. Am J Med Genet 2002; 107: 81-83.

12 de Vries BBA, van den Ouweland AMW, Mohkamsing $S$ et al: Screening and diagnosis for the fragile $\mathrm{X}$ syndrome among the mentally retarded: an epidemiological and psychological survey. Am J Hum Genet 1997; 61: 660-667.

13 Kleefstra T, Yntema HG, Oudakker AR et al: De novo MECP2 frameshift mutation in a moderately retarded boy. Clin Genet, 2002; 61: 359-362

14 Glatt CE, DeYoung JA, Delgado S et al: Screening a large reference sample to identify very low frequency sequence variants: comparisons between two genes. Nat Genet 2001; 27: $435-438$. 
15 Jeanpierre M: Pathogenic mutation or low-frequency polymorphism? Frequency of a DNA variant not found in $n$ chromosomes is less than 3 divided by n. (In French). Ann Genet 1996; 39: 133138.

16 Moncla A, Kpebe A, Missirian C, Mancini J, Villard L: Polymorphisms in the C-terminal domain of MECP2 in mentally handicapped boys: implications for genetic counselling. Eur $J$ Hum Genet 2002; 10: 86-89.
17 Cheadle JP, Gill H, Fleming N et al: Long-read sequence analysis of the MECP2 gene in Rett syndrome patients: correlation of disease severity with mutation type and location. Hum Mol Genet 2000; 9: 1119-1129.

18 Wan M, Lee SSJ, Zhang X et al: Rett syndrome and beyond: recurrent spontaneous and familial $M E C P 2$ mutations at $\mathrm{CpG}$ hotspots. Am J Hum Genet 1999; 65: 1520-1529. 